\title{
Sindrome de ojo rojo
}

\author{
Red eye syndrome \\ Augusto B. Chafloque-Cervantes ${ }^{1}$
}

\section{Resumen}

Uno de los problemas clínicos que el médico en una emergencia enfrenta diariamente es el ojo rojo. La mayoría de los casos son relativamente benignos y autolimitados; sin embargo, algunas condiciones están asociadas con alta morbilidad y son potencialmente amenazantes para la visión y pueden manifestarse inicialmente como ojo rojo. El médico debe estar atento a buscar los factores de alto riesgo en la historia clínica y en el examen, para determinar aquellos casos que pueden ser tratados en la emergencia sin la intervención del oftalmólogo y de otros que deben ser evaluados por el especialista de manera urgente por el peligro inminente de pérdida visual. El diagnóstico diferencial del ojo rojo es extenso, sin embargo, los casos más frecuentes incluyen: las conjuntivitis de múltiple etiología, las hemorragias subconjuntivales, epiescleritis, escleritis, uveitis anterior y glaucoma agudo congestivo de ángulo cerrado, que es una de las emergencias más importantes en medicina.

Palabras clave: Ojo rojo, conjuntivitis, escleritis, glaucoma agudo congestivo.

\section{Abstract}

One of the clinical problems that the doctor in an emergency faces daily is the red eye. Most cases are relatively benign and self-limiting; however, some conditions are associated with high morbidity and are potentially threatening to vision and may initially manifest as a red eye. The doctor must be attentive to look for the high risk factors in the clinical history and the examination, to determine those cases that can be treated in the emergency without the intervention of the ophthalmologist and others that must be evaluated by the specialist urgently because of the imminent danger of visual loss. The differential diagnosis of the red eye is extensive, however, the most frequent cases include: conjunctivitis of multiple etiology, subconjunctival hemorrhages, episcleritis, scleritis, anterior uveitis and acute angle-closure congestive glaucoma, which is one of the most important emergencies in medicine.

Keywords: Red eye, conjunctivitis, scleritis, acute congestive glaucoma.

\section{Introducción}

Si se realiza una encuesta a los médicos de emergencia sobre su consulta diaria, probablemente una de las causas que con mayor frecuencia enfrentan, es el ojo rojo. Si bien es cierto que puede constituir un signo alarmante, también es cierto que en la mayoría de los casos se deben a causas relativamente benignas. Por ello es de suma importancia que los médicos podamos diagnosticar oportunamente y con eficacia las causas de ojo rojo.

Es necesario lograr un abordaje eficiente, a fin de reducir la preocupación y ansiedad en los pacientes, así como disminuir las potenciales complicaciones que pueden derivarse de aquellas que acarrean peligrosidad. En el presente artículo se exponen algunas causas comunes del ojo rojo, pero existen otras que serán de responsabilidad de cada uno de los que practicamos la medicina y que significa buscar, conocer, lograr, diagnosticar y discriminar las que requieren su referencia urgente al especialista.

\section{Conjuntivitis}

Constituye una de las causas más frecuentes de ojo rojo y es producida por inflamación de la conjuntiva. Se clasifica basada en el agente etiológico y el tiempo de evolución de la enfermedad. Las causas más frecuentes de conjuntivitis aguda (menor de 4 semanas) son alérgicas, virales y bacterianas. La conjuntivitis alérgica responde a una reacción mediada por IgE, usualmente estacional relacionada al polvo y/o alérgenos derivados de animales. Los síntomas incluyen prurito, lagrimeo y rinorrea $^{(1,2)}$. El no presentar prurito aleja la posibilidad de que se trate de una conjuntivitis alérgica. El paciente puede presentar otras formas de atopia como asma, dermatitis o rinitis alérgica. En el examen físico hay inyección conjuntival

${ }^{1}$ Médico Oftalmólogo. Maestro y Doctor en Medicina Profesor Principal y Jefe de Postgrado en Oftalmología Universidad Nacional Mayor de San Marcos, Jefe del Servicio del Instituto Materno Perinatal. Académico de número Academia Peruana de Cirugía. 
bilateral y si existe secreción, es acuosa ${ }^{(3)}$. En el tratamiento debe evitarse la exposición a los agentes desencadenantes y puede utilizarse compresas frías, vasoconstrictores, antinflamatorios no esteroideos oculares y en algunos casos antihistamínicos orales ${ }^{(2)}$.

Las conjuntivitis infecciosas pueden tener varias etiologías. Las infecciones virales están dentro de las más frecuentes. La forma de transmisión es por los dedos, instrumentos médicos y piscinas. Su aparición común es en brotes en escuelas, centros laborales y de salud. El paciente refiere irritación que inicia en un ojo y que compromete el otro ojo en pocos días. Los hallazgos comunes pero no específicos incluyen linfadenopatía preauricular, inyección conjuntival generalizada, secreción acuosa y una reacción folicular de la conjuntiva tarsal inferior ${ }^{(2,4)}$. No tiene tratamiento especifico y en la mayoría debe incluirse compresas frías, lágrimas artificiales y colirios vasoconstrictores para proporcionar alivio sintomático ${ }^{(5)}$. Se debe recomendar al paciente realizar lavado de manos frecuentemente y no compartir toallas u otros artículos de higiene de uso común. En los casos que no existan mejoría en la primera semana deben ser referidos al oftalmólogo $^{(6)}$. La conjuntivitis por Herpes Simple puede presentarse aislada o bien ser acompañada de lesiones que afectan el párpado y la piel; usualmente, es unilateral. Se presenta con más frecuencia en los pacientes con infecciones generales y/o inmunodeprimidos. Para el tratamiento en casos, sin compromiso cutáneo y de la córnea, se emplea compresas frías y agentes antivirales tópicos. Los pacientes con lesiones pustulosas herpéticas en la punta de la nariz (signo de Hutchinson) tienen doble riesgo de compromiso ocular ${ }^{(8)}$. Si existe compromiso cutáneo, fotofobia y disminución de la agudeza visual el oftalmólogo al realizar tinción corneal, con fluoresceína sódica al 2\% observa lesiones puntiformes o dendríticas en la córnea, signo patognomónico de la queratitis herpética simple ${ }^{(10)}$. El tratamiento consiste en antivirales como Aciclovir oral $400 \mathrm{mg}$ cinco veces al día durante 7 a 10 días ${ }^{(11)}$. No se debe prescribir esteroides por el riesgo de incrementar infecciones secundarias y otras complicaciones ${ }^{(7,9)}$. En la infección ocular por clamidia existen los serotipos denominados $\mathrm{A}$ a $\mathrm{C}$, que es causa de tracoma ocular, entidad endémica en algunas zonas de la selva y sierra. La queratoconjuntivitis tracomatosa crónica en algunos países del sur asiático y áfrica, es la causa más frecuente de ceguera infecciosa prevenible. La conjuntivitis de inclusión es generada por serotipos del D hasta el $\mathrm{K}$, y frecuentemente es de transmisión sexual o vertical ${ }^{(2,10)}$.

La conjuntivitis por Gonorrea tiene una mayor incidencia en neonatos que la gonorrea materna porque la madre muchas veces es portadora asintomática. Debe recordarse que en todos los partos vaginales es obligatoria la prevención de la conjuntivitis gonocócica con la denominada "maniobra de Credé", en la cual actualmente se usa un antibiótico local. En el recién nacido se presenta con lagrimeo, inyección conjuntival, edema palpebral, secreción moderada en la primera semana después del nacimiento. La conjuntivitis causada por neisseria gonorrhoeae ocurre con más frecuencia en personas activas sexualmente. En el ojo del adulto puede presentar ojo rojo, sensación de cuerpo extraño, secreción muco purulenta y adenopatía preauricular. Se trasmite por vía genital-mano-ojo, pero los recién nacidos lo adquieren en el canal de parto. En el adulto existe la característica de que la descarga purulenta bilateral rápidamente se forma de nuevo después de la limpieza ocular. Se debe realizar frotis y cultivo para gérmenes gram negativos lo que confirma el diagnóstico. El uso de antibióticos es similar a las demás conjuntivitis bacterianas siendo recomendable iniciar tratamiento sistémico debido a la posible existencia de enfermedad genital asintomática. Además, es importante referir a estos pacientes al oftalmólogo porque puede complicarse con una ulcera y perforación corneal $^{(9,12)}$. En la infección genital asintomática del adulto se deberá administrar tratamiento con 1 gramo de azitromicina oral o doxiciclina $100 \mathrm{mg}$ dos veces al día durante 7 días y se deberá considerar el tratamiento preventivo a la pareja sexual. En estos casos la eritromicina tópica 2 a 3 veces al día por 2 a 3 semanas es efectiva ${ }^{(13)}$.

En las conjuntivitis bacterianas causadas por organismos gram positivos, las más frecuentes son por seudomona pneumoniae y estafilococo aureus y en los gram negativos es el hemofilus influenzae $e^{(10,14)}$. Tienen un inicio más abrupto que la viral y usualmente contamina al otro ojo en menos de 48 horas. Se presenta con secreción amarillenta mucosa, inyección conjuntival difusa ${ }^{(9,15)}$. El tratamiento es con antibióticos tópicos de amplio espectro, como la tobramicina, ciprofloxacina y la gentamicina, sobre todo en los gérmenes gran negativos ${ }^{(2)}$.

\section{Epiescleritis}

La epiescleritis, inflamación focal de epiesclera casi siempre está asociada a enfermedades del colágeno: Artritis Reumatoide, Lupus eritematoso sistémico, poliarteritis nodosa, granulomatosis de Wegener y otras como la enfermedad inflamatoria intestinal, sarcoidosis, gota, sífilis e infecciones sistémicas por Herpes Virus. Se caracteriza por su rápido inicio de ojo rojo focal, sensación de cuerpo extraño y cefalea. La visión no se afecta y no presenta secreción. Al examen, se observa área de congestión focalizada de color rojizo $^{(16)}$. Esta patología es usualmente autolimitada y se resuelve en la mayoría de los casos dentro de las 2 a 3 semanas. El tratamiento incluye AINES y/o corticoides orales y tópicos; los agentes lubricantes pueden ser útiles ${ }^{(10)}$.

\section{Escleritis}

Es la inflamación de la esclera que puede comprometer también a la córnea y a la úvea. Usualmente se presenta en mujeres de edad media y es característico el dolor ocular severo que se irradia a la cara, la oreja, y la cabeza ${ }^{(10)}$. Puede presentarse en el polo anterior y posterior del ojo. La escleritis anterior se subdivide en nodular, difusa y necrotizante. La variante difusa es caracterizada por edema escleral extenso y congestión de los vasos esclerales. La escleritis nodular anterior es focal, con nódulos bien definidos. La variante 
necrotizante se caracteriza por presentar un área avascular de necrosis escleral y presenta inflamación significativa del área alrededor de la lesión. Esta entidad conlleva el peligro de perforación ocular. La escleritis posterior se encuentra localizada entre los músculos rectos extraoculares y puede estar asociada a escleritis anterior. Esta entidad es mediada inmunológicamente, precipitada por infecciones, por cirugía,

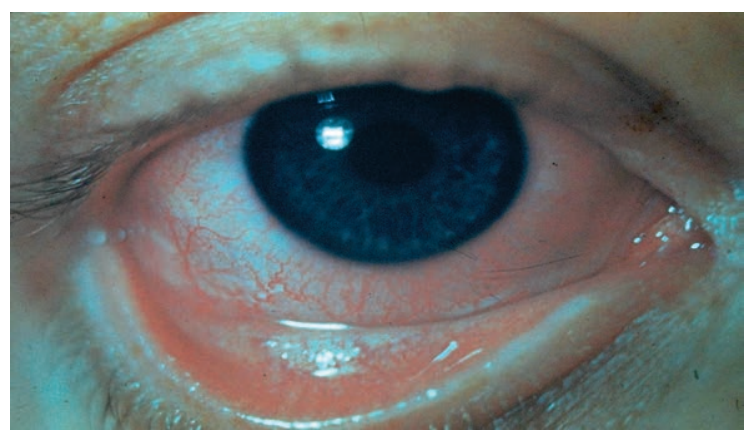

Conjuntivitis viral.

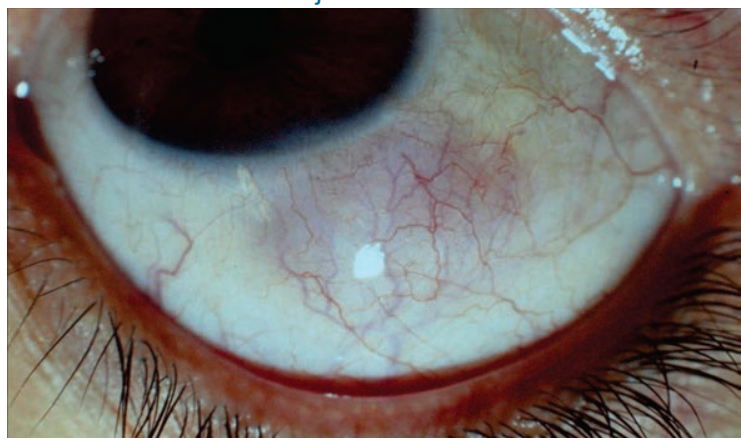

Epiescleritis.

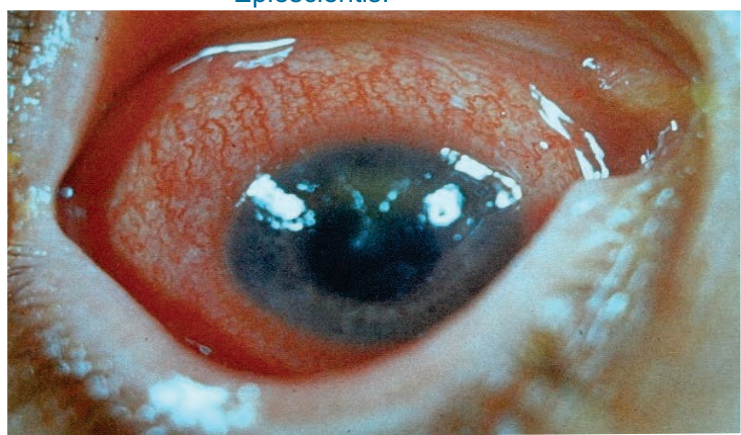

Keratol-uveitis aguda.

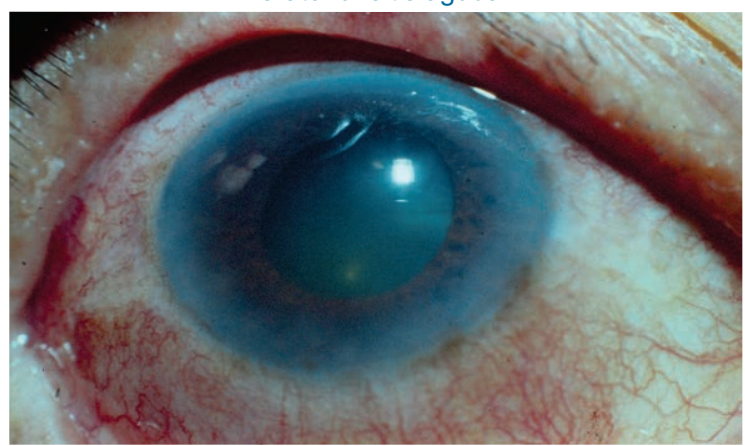

Glaucoma Agudo congestivo. por reacciones adversas a determinadas medicamentos y principalmente por la artritis reumatoide. La granulomatosis de Wegener es la vasculitis más frecuente asociada a esta condición y la que conlleva más peligro de perforación ocular. También se incluye como causa de escleritis al lupus eritematoso sistémico, poliarteritis nodosa, síndrome de Reiter, enfermedad inflamatoria intestinal y la esclerosis sistémica

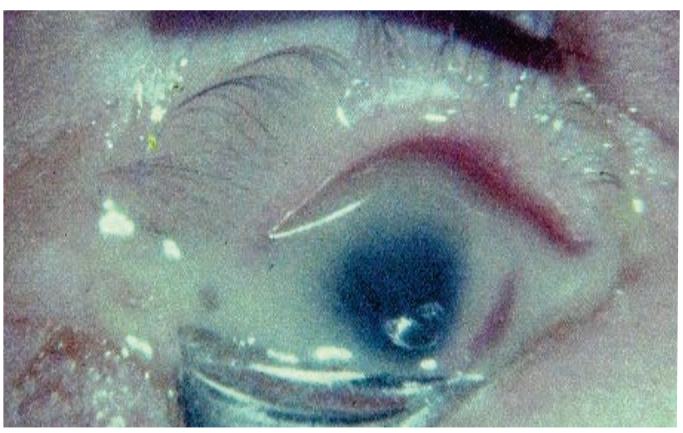

Conjuntivitis gonocócica.

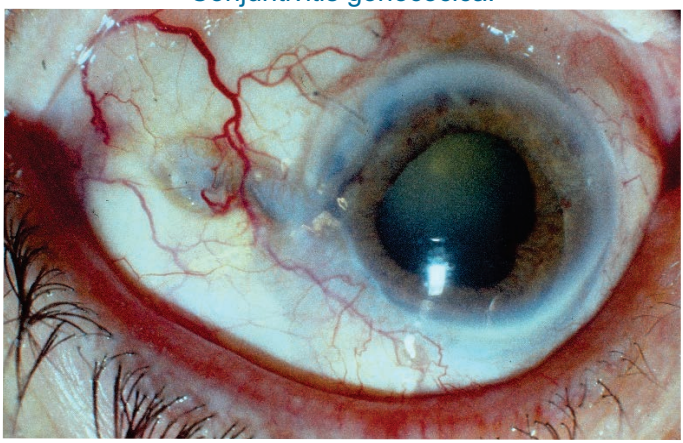

Escleritis Necrotizante.

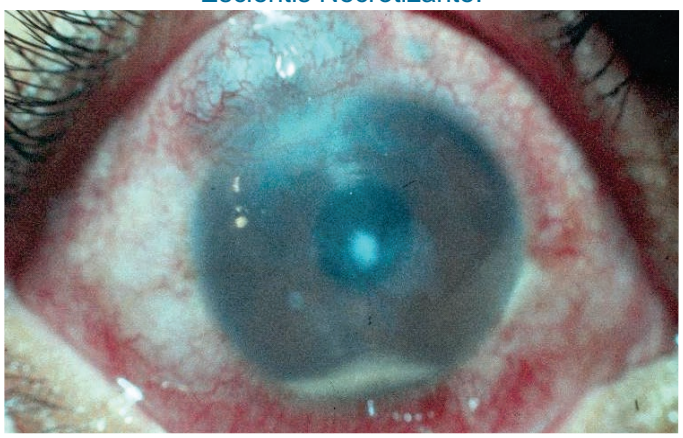

Uveitis, Hipopion, Endoftalmitis.

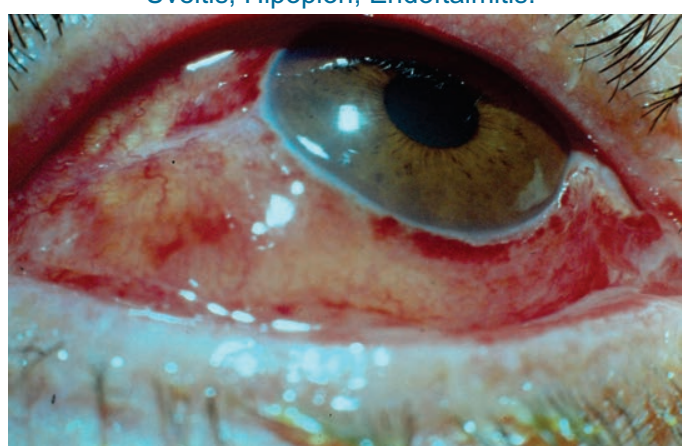

Hemorragia subconjuntival. 
progresiva $^{(11)}$. Otros posibles agentes infecciosos, son la sífilis, tuberculosis miliar, Pseudomona aureginosa, Virus de Epstein Bar y virus Coxsackie B5. La presencia de edema escleral y congestión del plexo escleral que no cede a los vasoconstrictores locales es el hallazgo distintivo de esta entidad ${ }^{(10)}$. Es importante su diagnóstico precoz para disminuir la posibilidad de complicaciones como la presencia de uveítis anterior, queratitis ulcerativa, catarata y glaucoma secundarios. En caso de cualquier tipo de escleritis es obligatoria la evaluación minuciosa del oftalmólogo quien deberá iniciar el tratamiento ocular y multidisciplinario de la enfermedad de base ${ }^{(18)}$.

\section{Hemorragia Subconjuntival o Hiposfagma}

Es el sangrado por ruptura de los vasos conjuntivales o epiesclerales hacia el espacio subconjuntival. Puede ser espontánea, asociada a traumatismo ocular y a una enfermedad sistémica. Cuando es espontánea, es secundaria a fragilidad capilar, Diabetes Mellitus, Hipertensión arterial y problemas de coagulación sanguínea. Se presenta como un ojo rojo indoloro sin afectar la visión, sin secreción asociada y puede existir historia de trauma leve o haber realizado la "maniobra de Válsalva". Al examen aparece la sangre fresca en la parte blanca del ojo, entre la conjuntiva, membrana transparente y la esclera. Tiene bordes delimitados y puede extenderse lentamente y si es intensa puede aparecer en la piel del parpado inferior. Si la hemorragia ocurre posterior a un trauma, puede haber lesión penetrante en el globo ocular, la cual podría estar oculta por la hemorragia y se requiere una evaluación oftalmológica. Para las hemorragias subconjuntivales de menor cuantía no es necesario tratamiento pero se debe informar al paciente, que la hemorragia desparecerá de 1 a 2 semanas. Este tipo de hemorragia no requiere referencia al oftalmólogo ${ }^{(14,15)}$.

\section{Uveítis anterior}

Esta entidad se produce por inflamación de la capa media del ojo úvea: iris y cuerpo ciliar ${ }^{(18)}$. Las causas pueden ser inflamatorias, traumáticas e infecciosas; las hay de etiología desconocida considerándosele como entidad autoinmune. Se le ha asociado con el antígeno de histocompatibilidad HLA B27 por lo tanto se presenta en las afecciones articulares como la espondiloartrosis. También se presenta en la sarcoidosis, Artritis juvenil, enfermedad de Bechet, Enfermedad de Kawasaki, esclerosis múltiple y granulomatosa de Wegener ${ }^{(18,19)}$. Enfermedades parasitarias como la toxoplasmosis, virales como citomegalovirus, herpes zoster, bacteriales como tuberculosis, enfermedad de Lyme y sífilis pueden ser responsables de esta patología. Usualmente, se presenta con dolor agudo y profundo que se irradia al área periorbitaria. $\mathrm{Su}$ característica: fotofobia, inyección conjuntival periquerática, y casi siempre acompañada de visión borrosa. El dolor empeora con los movimientos oculares y la acomodación. La hiperemia es prominente en la región del limbo esclero-corneal. La pupila se encuentra miótica, respuesta lenta a la luz y tendencia a las sinequias iridolenticulares. Un hallazgo importante es la fotofobia directa y consensual al proyectar luz en el ojo no afectado. Estos casos deben ser obligatoriamente evaluados por el oftalmólogo para su correcto diagnóstico etiológico y su tratamiento definitivo ${ }^{(5)}$.

\section{Glaucoma de Ángulo Cerrado}

Esta condición que se produce cuando el iris bloquea el flujo de salida del humor acuoso lo cual ocasiona elevación abrupta de la presión intraocular con dolor ocular severo, marcado enrojecimiento, disminución de la visión y dilatación fija de la pupila. Antes del cuadro definitivo se presenta visión borrosa, visión de halos alrededor de las luces, cefalea, náuseas y vómitos. El ataque agudo, raras veces, puede ser autolimitado y ocurrir repetidamente. Las personas de la tercera edad son de más alto riesgo. Al examen se presenta marcada inyección pericorneal, y lagrimeo. Uno de los hallazgos más importantes es la pupila muy dilatada y no reactiva a la luz ${ }^{(10,13)}$. La presión intraocular que normalmente es menor a $20 \mathrm{~mm} \mathrm{Hg}$. esta sumamente elevada. En la sospecha de glaucoma agudo, el médico debe pedirle al paciente que cierre sus ojos y que dirija la mirada hacia abajo, y el examinador hará una presión ligera con los dedos índices en el globo ocular afectado (presión digital) a través del párpado en la cual notará una gran diferencia en la "dureza" o tensión del globo ocular enfermo ${ }^{(5,10)}$. El tratamiento requiere la rápida referencia al oftalmólogo ${ }^{(13)}$. En caso de ausencia de éste, deberá administrar glicerina oral $1.5 \mathrm{ml}$ por $\mathrm{Kg}$ de peso, que tiene efecto deshidratante inmediato y luego una tableta de acetazolamida para disminuir la producción del humor acuoso. Asimismo, debe tratarse los síntomas sistémicos como la cefalea y los vómitos para lo cual se podrá utilizar antieméticos y analgésicos sistémicos ${ }^{(20)}$. El tratamiento definitivo que es quirúrgico, lo realiza el oftalmólogo con iridectomía periférica y/o iridotomía Laser con el objetivo de comunicar la cámara anterior con la posterior y desbloquear la pupila. El ojo contralateral debe recibir iridotomía profiláctica, debido a que aproximadamente la mitad de los pacientes presentarán glaucoma de ángulo cerrado en su otro ojo dentro de los 5 años posteriores al evento. En el diagnóstico diferencial debe considerarse en los casos de migraña y jaqueca en los que no existen los síntomas descritos anteriormente ${ }^{(9,14)}$.
1.Bielory L. Allergic Diseases of the Eye. The Medical Clinics of North America 2016;90:129-48.

2.Bielory L. Ocular Allergy Overview. Inmmunoly and Allergy Clinics of North America 2008;28:1-23.
3. Bielory L. Ocular Allergy Treatment. Immunology and Allergy Clinics of North America 2008;28:189-224.

4. Galor A, Thorne J. Scleritis and Peripheral Ulcerative Keratitis. Rheumatic Disease Clinics of North America 2015;33:835-54. 
5.Hajj-Ali RA, Lowder C, Mandell BF. Uveitis in the internist's office: are a patient's eye symptoms serious? Cleve Clin J Med 2015;72(4):329-39.

6.Knoop KJ, Dennis WR. Ophthalmologic procedures. In: Roberts JR, Hedges JR, editors. Clinical procedures in emergency medicine. 4th Edition. Philadelphia: Saunders; 2004; 1241-79.

7. Kunimoto DY, Kanitkar KD, Makar MS, editors. The Wills eye manual: office and emergency room diagnosis and treatment of eye disease. 8th Edition. Philadelphia: Lippincott Williams \& Wilkins; 2014:61,91,98,155,179-81.

8. Magauran B. Conditions Requiring Emergency Ophthalmologic Consultation. Emergency Clinics of North America 2008;26:233-38

9. Mahmood A, Narang A. Diagnosis and Management of the Acute Red Eye. Emergency Medicine Clinics of North America 2008;26:35-55-

10.Naradzay J, Barish R. Approach to Ophthalmologic Emergencies. The Medical Clinics of North America 2006;90: 305-28.

11. Okhravi N, Odufuwa B, McCluskey P, et al. Scleritis. Surv Ophthalmol 2005;50(4):351-63.

12.Prentiss K, Dorfman D. Pediatric Ophthalmology in the
Emergency Department. Emergency Medicine Clinics of North America 2018;26):181-98.

13. Robinett D, Kahn J. The Physical Examination of the Eye. Emergency Medicine Clinics of North America 2018; 26: 1-16.

14. Roscoe M, Landis T. How to diagnose the acute red eye with confidence. JAAPA2 2006 2003;19(3)24-30.

15. Roy FH. The Red Eye. Ann. Ophthalmologic. 2006;38(1):358.

16. Sowka JW, Gurwood AS, Kabat AG. Episcleritis.Handbook of ocular disease management. Web Site 2000. Disponible en: http://www.revoptom.com/HANDBOOK/sect2f.htm

17. Carter III W, C. Germann C, Baumann M. Ophthalmic Diagnoses in the Emergency Departments: herpes zoster ophthalmic. American Journal of Emergency Medicine 2016;26: 612-17.

18. Wagner R., Aquino M. Pediatric Ocular Inflammation. Inmmunoly and Allergy Clinics of North America 2014;28:169-88.

19. Walling AD. Tips from other journals: when is red eye not just conjunctivitis? Am. Fam. Physician 2012;66(12):2299- 2300.

20. Wu I, Schwartz A. Reiter's Syndrome: the classic triad and more. Journal of American Academy of Dermatology. 2008:113-21.

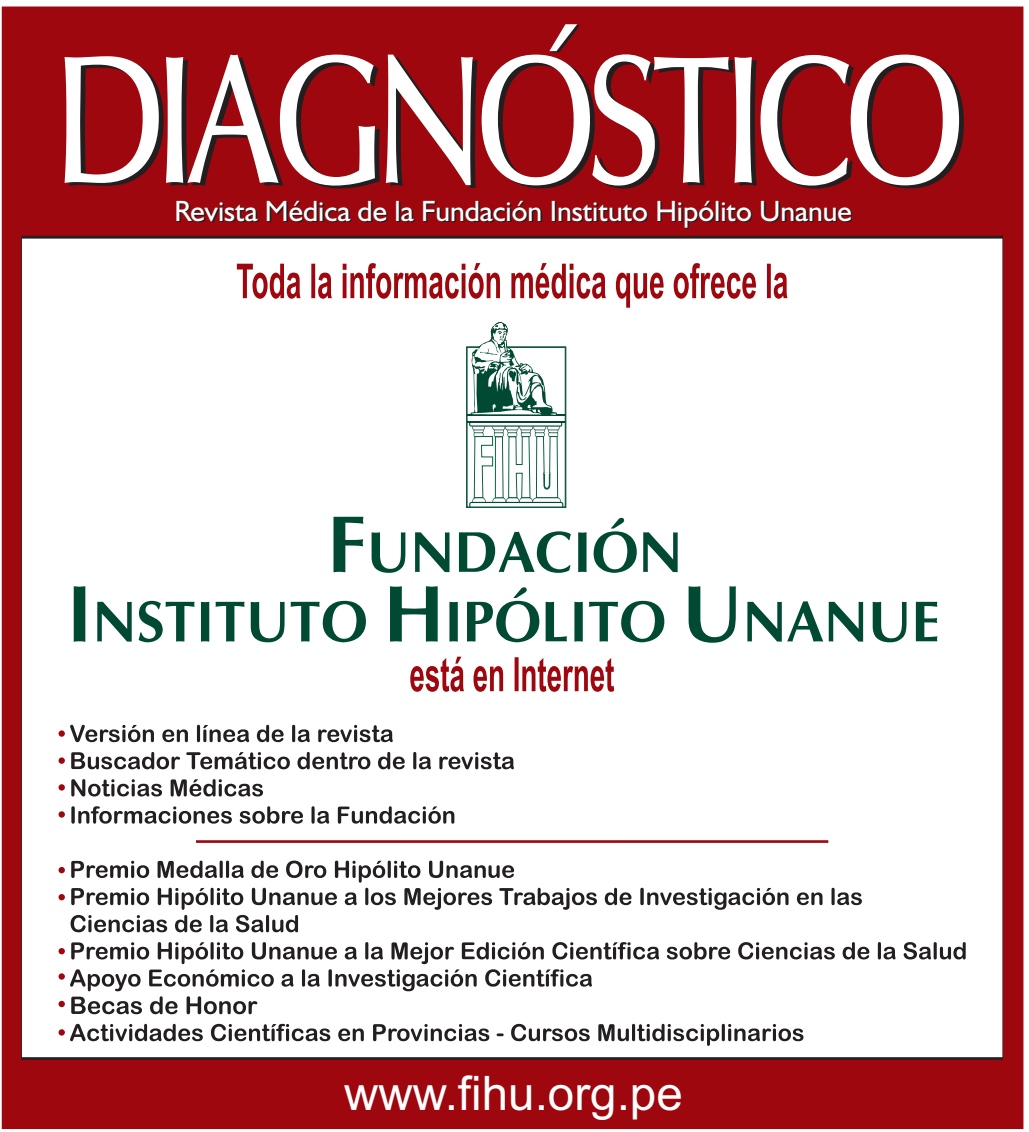

